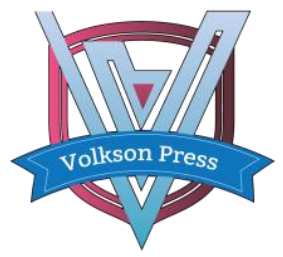

\title{
INNOVATION AND PRACTICE OF THE MICRO TRANSFORMATION OF THE "THREE OLD" COMMUNITY IN WUHAN-A EXAMPLE OF SHUIGUOHU STREET COMMUNITY RECONSTRUCTION OF WUCHANG DISTRICT
}

\author{
Jing Chen, Yue Wang, Ran Xiao, XiaoXiao Zeng \\ Huazhong University of Science and Technology, Luoyu Road, Wuhan,China \\ *Corresponding Author's E-mail: melindachenj@163.com
}

This is an open access article distributed under the Creative Commons Attribution License, which permits unrestricted use, distribution, and reproduction in any medium, provided the original work is properly cited.

\section{ARTICLE DETAILS}

\section{Article History:}

Received 12 March 2018 Accepted 12 April 2018

Available online 15 May 2018

\section{ABSTRACT}

At the thirteenth Congress of the Wuhan city of the Communist Party of China, Chen Yixin, Secretary of Wuhan Municipal Committee, put forward the system of "three old" transformation that explore and promote the transformation of old communities, historical and cultural communities and complete the reconstruction of the village in central urban area. The important proposition puts forward requirements for our "three old" community transformation road. Facing the new requirements of urban construction objectives and tight land resources. Facing the new conditions of urban building goal and land resource tension. The community in Wuhan is turning to the stage of "reverse growth" development mode that pays more attention to quality and vitality and put forth effort to improve the environmental quality and community spirit of stock space. "Community micro transformation" is based on the public space and public service facilities of old communities to explore a new method to improve residents' daily life and participation under the premise of no adjustment of the planning index.

\section{KEYWORDS}

urban renewal, "Three old" communities, Community micro transformation, Public participation, Wuhan.

\section{INTRODUCTION}

Based on a study, with the development of the times, old communities have gradually been eliminated. The transformation of old communities has gradually become the focus of urban transformation and development and urban planning [1]. The is urgent to actively explore and establish new mechanisms and systems, and gradually guide the more rationalization and legalization of community governance for create a truly characteristic community model belonging to Wuhan [2]. Taking the transformation of fruit lake community in Wuchang District of Wuhan as an example, the present paper explores a suitable implementation path of Wuhan's "three old" community micro transformation plan [3]. Through case studies and analysis, this article focuses on the research and analysis of Shiquan Road street community and Siping Road street community in Putuo District of Shanghai, focusing on the protection and transformation of historical and cultural communities, including Beijing Juer Hutong and old residential areas. The parties involved in the transformation of the implementation path and the actual effect. Attempts to explore the implementation mechanism of micro-renewal in the "three old" communities in Wuhan include Demand-oriented Planning, "Respace", Microscopic Observation and Analysis of Behaviors [4]. Finally, with reference to these research methods, we will improve facilities and repair houses, and arrange transportation to improve the environment.

\section{RESEARCH RESULTS ANALYSIS OF COMMUNITY MICRO REFORM}

Ju'er Hutong in Beijing based on the protection and transformation of historical and cultural communities. Ju'er Hutong" is one of the 21 reconstruction areas of the old house that designated by Beijing municipal government in 1986, whose main problems are shown in the following three aspects, including crowded population and housing difficulties, serious aging of housing and backwardness and shortage of living facilities. Wu Liangyong, the director of Architecture Department of
Tsinghua University, the famous architect and urban planning expert, leaded a group of people, replacing the traditional quadrangle with the new courtyard house mode according to its texture, who won numerous awards and accolades such as the UN Habitat Award [5].

The of implementation path of Beijing Ju'er Hutong transformation based on the principle of urban texture control

(1) foliation regulation and construction to keep the integrity of this section of the area.

(2) strictly limiting the height of residential buildings (three layers).

(3) keeping elegant gray and white hue for residential buildings.

(4) maintaining the original chessboard road network and street alley system and inheriting and developing quadrangle house.

The actual utility of the parties involved in the transformation:
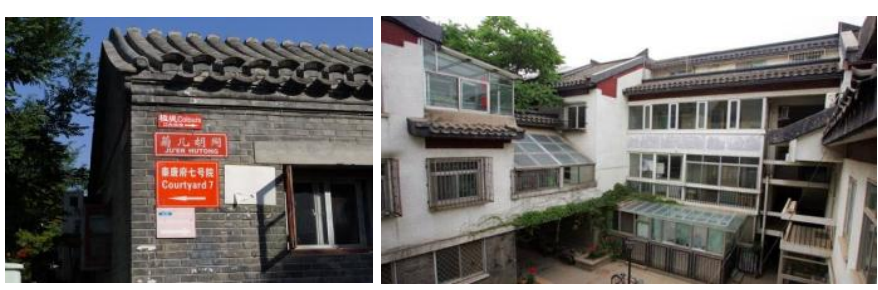

Figure 1: Before and after the transformation of Juer Hutong

"Ju'er Hutong" project is substantially an important step towards China's symbolic public participation and provides an exemplary role for dealing 
with the relationship between government, market and the public after the old city transformation. The overall transformation is based on the principle of "voluntary participation", carries out by extensive household survey and participation. It provides more generous compensation for the relocated housing and builds the first "residential cooperative" for organization of reconstruction of the old house in Beijing to achieve "fund building", which is an important exploration of "housing reform" in China [6]. However, residents are completely excluded from the construction process due to adopting the way of "resettlement in other places" in the project, so that there is no effect on construction. Therefore, whichever level of the design or the construction, It's success is mostly attributed to the ideal realization of planners, not the result of club ideas and exertions of the local residents.

\section{RECONSTRUCTING THE OLD RESIDENTIAL AREA IN SHIQUAN ROAD STREET COMMUNITY, SIPING ROAD STREET COMMUNITY OF PUTUO DISTRICT}

\subsection{Shiquan Road Street Community in Putuo District}

Shiquan Street owns 3.53 square kilometers of land. Through The streets and professional design teams carding in an inch and one inch, the first Street Renewal guideline in Shanghai is formed. In the limited space in the old community with inherent structure, by using local materials and adding creativity, we can scientifically and skillfully provide a plan that gives consideration to human needs and delivers local values [7].

\subsection{The results of investigation are as following}

The implementation path of community micro transformation based on the three steps of "green + paved + corridor" Shiquan Street community transformation were based on the knowing the real situation of the 84 residential quarters of the whole street, which cardes a list of more than 200 update items, and forms "Shiquan Street City Renewal Design Guidelines". From the road to the street, it is the return of motor vehicle traffic space to walking life space, it is the transformation from the right of the "vehicle" to taking into account the vehicle and walking and optimizing the walking environment. The change made more refined, humanized and intelligent new request to the planning, design and management of roads. The project goes from within the community to the outside street and from the old district to Shikumen, so that it carries out "walking Shanghai" project in 22 pilot projects within two years, involving old communities, streets, alleys, public facilities, public art and business circles. The map of the Shanghai micro - update pilot is widening.
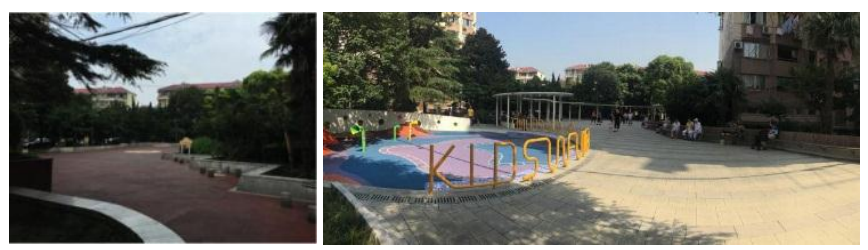

Figure 2: Community Plaza in Putuo District Shiquan Road Street

For example, Guannong village of Shiquan Road community in Putuo District owns the largest residential square across the streets, where the children can play freely in the children's paradise, and the elderly enjoy their unique old age in their well-designed "territories" that belong to themselves. The community's "micro renewal" has enriched the old community and the old residents. The actual utility of the participants in the transformation is as following:

Shiquan Road Street reform was conducted by the government and professional design team cooperation mode, and the professional design team coordinates streets to measure and card every inch of land, which forms the first guideline of systematic urban renewal promulgated by streets in Shanghai---"Shiquan Street City Renewal Design Guidelines". The guideline divides the transformation points into two parts: Street projects and open space projects. Among these, 36 reconstructive Street project and 28 reformed open space projects will be completed in the open space of the "13th Five-Year" period.

\subsection{Street community of Siping Road}

The Siping community is the elderly community in Shanghai, facing many problems such as shortage of venues, backward facilities and lack of sense of belonging. The goal of "creation action" in Siping Street is to transform old or inefficient public spaces in Siping community, to plan and design based on public participation and to create more details of public space.
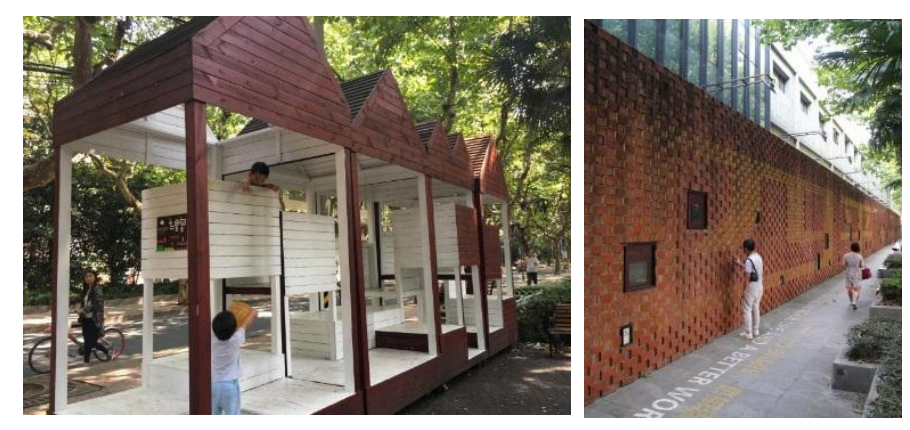

Figure 3: Siping community space creative space

The research project of the public space of "Siping community space creation action" invite designers, researchers, artists and university students from different fields to Siping community and make them explore boldly how to make use of design thinking and initiative design as driving force to link the old or inefficient public space in the community with daily life and community service. Because of this, it makes the residents feel and participate in the construction of life aesthetics, which improve the quality of public space to make it more alive and make it to be the shared space for the daily life of the community residents.

For example, the work "Left and right" makes use of the side texture of red brick wall. By the means of visual illusion, it creates different visual experience for walking from north to South and from south to north and describes the story of another walk. At the same time, it shows the close relationship between "Siping" and "D\&I" in geography and idea with a novel form of low-key. For the work based on theme of "Homestead" created In the Sujiatun Road, designers transplant home interior design to outdoor, forming a warm relaxing space, which make people have a sense of identity in public space.

In addition, community streets also have Marios, rhythm JUMPJUMPs, mobile seed houses, walls with the theme of the street talks, seats, newsracks, manhole covers, garbage rooms, street sculptures, green pieces, and so on. These things become more interesting and more dynamic after the co creation and reconstruction of designers and residents.

The actual utilities of the participants in the transformation are as following:

The establishment of long-term operation mode based on the cooperation between the government and the people is the premise for the healthy development of community spatial updating.

(1) Community construction through public participation mechanism The designer team looks for the resident representatives through the street government to learn residents' intentions and demands for public space transformation and link creative design to daily life and community service for improving the quality of community public space

(2) "Creative action" under the guidance of government power The role of the government is partners and supporters, which implies the transformation from "one way" regulation from traditional social management to interaction "governance". In the reform of community, the support and guidance provided by the government is closely related to the cooperation between the government and the people. The key to success is to mobilize social resources with government strength, public participation and nurturing community organizations. The construction of civil society and the degree of citizen participation are often closely related to the support density of government in aspects of administration, system and capital. In the long run, the government's guidance and assistance is an important guarantee for promoting the community transformation led by residents.

\section{THE PATH EXPLORATION OF THE MICRO TRANSFORMATION OF THE "THREE OLD" COMMUNITY IN WUHAN}

Based on the community micro update at home and abroad, we should enhance the quality of the space, what is more we should activate idle resources in communities, meet diverse needs of residents, and reestablish community's humanistic ecology, and then realize the sustainable development of the community [8]. Based on the above concept interpretation and reviews of related case studies, this paper explores community micro update path suitable for Wuhan. 
After the rapid spread and expansion of cities in the early 1990s and early twenty-first Century, land supply policy in our country is increasingly tightened. transformation from "growth expansion" to "stock optimization" is the new situation and new requirement that Wuhan and most large and medium-sized cities in China need to face in the current development stage.

Chen Yixin, deputy secretary of the provincial Party committee and Secretary of the Wuhan Municipal Committee at the Thirteenth Party Congress of Wuhan, Hubei, On January 2017, put forward in the report that we should let culture leads urban planning and construction, and promote urban cultural personality and taste, and systematically promote the transformation of "three old", and explore the Micro transformation of old communities and historical cultural blocks.". Since February 2017, in response to the Secretary's call, Wuhan Municipal Committee innovate and implement the "red engine project", which regards party construction leading the innovation of social governance at the grass-roots level as the key point and focus on promoting the construction of community innovation, and introduce high-quality service management team to coordinate with professional design units to speed up the transformation process of old communities and improve the quality of life of residents. "double repairs" of cities promoted by Wuhan's Ministry of housing also definitely puts forward the concept and measures of "urban patch".

\subsection{Analysis of operation mechanism}

At present, the participants in Wuhan's community construction mainly include:

(1) Government: It is a special organization that is elected by the people, giving power, providing financial resources and entrusted by the people to manage public affairs.

(2) Non-governmental organizations: It does not aim at profit and it is not political and independent. In addition, it is an organization that studies social development policies, participates in social affairs and serves the community, including (but not limited to) universities, social sciences research institutes, etc.

(3) Enterprises: its main work is the production or exchange all kinds of material and non-material products, to win to maintain the operation of the organization

(4) Community: It mainly refers to the residential area. A community organization selected by residents is a leader who manages various life activities and small production and circulation activities under the jurisdiction of the community.

\subsubsection{At the present stage, the operation mechanism of Wuhan's} community construction is based on the following two ways.

(1) One is government oriented governance model. The government takes the most part of community affairs independently, which is the main body of community governance.

(2) The other is government's governance mode combined with community autonomy. The NGOs and individuals in the community begin to participate in the process of community governance. The government department is the main promoter of community construction and management and plays a leading role in the process of community construction.

\subsection{Analysis of sources of funds}

The main source of funds for the transformation of "three old" communities in Wuhan is as following

(1) The government allocates funds for special transformation, which is also the main source of funding.

(2) Special funds for allocation and transformation in community public income such as property fee and parking fee.

(3) collective capital contribution of community residents.

\subsection{Analysis of community type}

The old communities in Wuhan can be divided into three types.
(1) Non property old community: The neighborhood committees are mainly responsible for the management of the neighborhood offices. There are more elderly, children and low-income people in the community, which makes difficult to transform, such as Zhangjiawan east second community in Wuchang District, Yuan Jia community Fourwei street Jiang'an District.

(2) Unit type old community: It is jointly managed by a unit and a street office, such as 117 community of green hill street in Qingshan District and it residents are mainly composed of in-service employees and family members.

(3) Old property management community: It is managed jointly by the property company and the street office, with relatively perfect infrastructure and the relatively high participation of residents, which is less is, less difficult to transform, such as Huajin community of Nanhu Street in Wuchang District.

\subsection{Analysis of transformation model}

\section{several modes of community renovation in Wuhan are as following}

(1) Maintenance type of community planning. This planning is mainly applied to communities with high use value. Based on the premise of maintaining the normal use of the house, we can improve the quality of life of community residents by improving the quality of community environment and public facilities.

(2) Building type of community planning. We can improve the living environment of the old community by reconstructing, expanding, partially demolishing, upgrading the public facilities or modernizing their homes in view of the status of old dwelling house.

(3) Reconstructive type of community planning. The reconstruction is to dismantle and clear up the old community that had no reserved value, replanning and designing, enhancing the housing volume rate, quality standard and living comfort, and improving the community's public facilities so as to improve the living function of the community.

\subsection{Existing problems analysis}

(1) chaotic for the road traffic system

The purpose of road design in old communities is mainly used for community residents' walking, unit transportation materials and firefighting needs. The classification of internal road is not obvious, and the internal traffic is evacuation. Some sub trunk roads are narrow, because it does not consider the demand for traffic. It is difficult for twoway traffic, the road is mostly used in the way of people and vehicles, the speed of traffic in the community is restricted, the sidewalk is narrow.

(2) Deficiency of public parking space

Since the early planning did not take into account the situation of traffic expansion in modern vehicles, the community did not consider a large area of parking function, usually planning a parking space for motorcycles, tricycles, etc. In the end of $90 \mathrm{~s}$, the newly built housing began to set up the underground parking garage, but it still could not meet the needs of the general residents because of the influence of use permission, limited number and convenience of parking. Therefore, there are still a lot of roadside parking. The phenomenon of which is very serious. It's not only occupying the driveway, but also occupying the sidewalk. The phenomenon of occupying the road is serious which not only occupy the car channel, but also more occupy the sidewalk.

\section{(3) A lot of unused space waste}

Most of the old community were built in the middle of the last century, so lots of the green vegetation in the community has grown for more than ten years or even several decades which mostly for the green space or pavement elevation. Part of the region is not conducive to development and construction, resulting in space waste. At the same time, there are private housing, private construction and occupy public space in old residential areas.

\section{(4) Lack of public space}

The old community has built a community external activity space for residents' entertainment and leisure, which is generally concentrated in the center of the community, so that the residents can participate in the use. However, today's environmental quality is worse than before, sparsely populated and low utilization rate, because of neglecting of 
management and maintenance.

\section{THE IMPLEMENTATION MECHANISM OF "THREE OLD" COMMUNITIES RESPACE IN WUHAN CITY}

New thoughts are gained on the planning of the "three old" communities in Wuhan after investigations of respace communities both at home and abroad. The purpose is to improve the quality of community space, but more importantly, to activate the community's idle resources, meet the diverse needs of residents and restore the human ecology of the community, thus realizing the sustainable development. Based on summaries of the domestic and foreign cases, this paper attempts to explore two categories of implementation mechanisms for the respace of "three old" communities in Wuhan, and four aspects are included.

\subsection{Demand-oriented Planning}

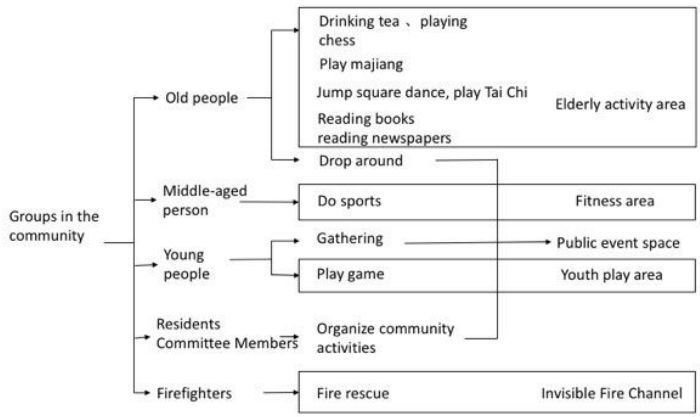

Table 1: Activity-space diagram based on various groups in the communit

The community population is divided into five groups. Different groups have different living patterns, and the direction of community space construction is guided by the residents' living demands. Residents are asked to decide the communities that require improvement and then issues of concern will be collected, respace plans will be formulated and comprehensive assistance, such as funds and management will be provided. Exchanges with community residents and managers are also necessary. In the first step, the joint working group learns about the basic conditions of the community, including community development history, population structure, environment, social relations, etc., from neighborhood committee, property office and owners' committee. In the second step, after field research, aging and livable communities, public facilities for the elderly shall be constructed, refined services shall also be provided, which are the shared desire of the four communities on Fruit Lake Street (Table 1).

Table 2: Type of Fruit Lake Community and Resident Demand

\begin{tabular}{|l|l|l|l|l|}
\hline & $\begin{array}{l}\text { Zhangilawan } \\
\text { Community }\end{array}$ & $\begin{array}{l}\text { Tea Port } \\
\text { Community }\end{array}$ & $\begin{array}{l}\text { Dongting } \\
\text { Community }\end{array}$ & $\begin{array}{l}\text { Wuzhong } \\
\text { Community }\end{array}$ \\
\hline Construction age & $\begin{array}{l}\text { 20th century 70- } \\
80 \mathrm{~s}\end{array}$ & $\begin{array}{l}\text { 20th century 70- } \\
80 \mathrm{~s}\end{array}$ & $\mathbf{1 9 8 5}$ & 2015 \\
\hline $\begin{array}{l}\text { Nature of the } \\
\text { house }\end{array}$ & Welfare house & Welfare house & Welfare house & $\begin{array}{l}\text { Commercial } \\
\text { housing }\end{array}$ \\
$\begin{array}{l}\text { Household } \\
\text { situation }\end{array}$ & $\begin{array}{l}\text { Mostly old } \\
\text { people }\end{array}$ & $\begin{array}{l}\text { Mostly old } \\
\text { people }\end{array}$ & $\begin{array}{l}\text { Mostly old } \\
\text { people }\end{array}$ & $\begin{array}{l}\text { Mostly young } \\
\text { people }\end{array}$ \\
\hline Main demand & $\begin{array}{l}\text { Building an old- } \\
\text { age and livable } \\
\text { community }\end{array}$ & $\begin{array}{l}\text { Building an old- } \\
\text { age and livable } \\
\text { community }\end{array}$ & $\begin{array}{l}\text { Building an old- } \\
\text { age and livable } \\
\text { community }\end{array}$ & $\begin{array}{l}\text { Building an old- } \\
\text { age and livable } \\
\text { community }\end{array}$ \\
\hline
\end{tabular}

From the problems reflected by residents, it can be seen that certain spatial problems can be solved by professional abilities of designers, such as the construction of sport field in the community, the improvement of children activity yard, the number of outdoor seats, and the widening of roads. But the rest problems not only require designers to generate strategies, but also the coordination of government and residents, such as public transport, housing repair, parking management, community health and so on. Even though these problems are not visible, they have seriously affected the quality of life of the residents, which need to be solved urgently.

\subsection{Microscopic Observation and Analysis of Behaviors}

Microscopic observation and analysis is conducted on the basis of behavioral research. The research focus of next step is mental health needs of the elderly in the community, starting from empathy, the behavioral activities of the elderly are observed, and deep conversations are exchanged. By doing this, the mental health needs of the elderly in our mind and the actual mental health needs of the elderly can be distinguished, and their true ideas can also be learned. Furthermore, real problems can be discovered and redefined by collecting relevant information, as a result, clear and concrete planning and solutions can be established. In the following, the elderly shall be asked to experience scenario prototype tests and give comments, thus improving the scenarios. "Empathy", "Definition", "Imagination", "Prototype" and "Testing" run through the entire community renovation project (see diagram). The core of the project is to explain the ideas of others and our own through storytelling. In addition, residents are inspired to discover practical problems in the game-style way, so as to improve their ability of solving problems, searching happiness and beauty, discovering and enjoying the beauty of community life.

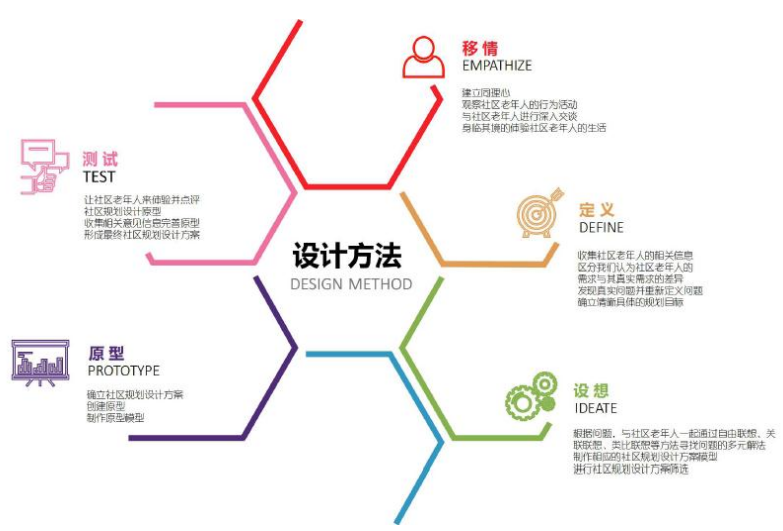

Table 3: Schematic diagram for the planning and design of community renovation project

\section{3 "Respace"}

Space regeneration refers to use limited community space thoroughly. The community respace absolutely not means large-scale demolition or reconstruction, but to tap underutilized public space in the community, such as idle public buildings, underground space, negative square green, etc. Within the limits of relevant laws and regulations, the progressive way is advised, also known as "acupuncture", so that the communal space is colorful, entertained, sociable and vital. The following respace approaches is recommended to be adopted, namely, low-cost, low-threshold, wideparticipation, multi-cooperation, easy-to-use, practice-oriented, eliteoriented, action-oriented, integrated-oriented and problem-oriented. In this way, the vitality of community can be stimulated. The main targets of respace are idle public spaces or buildings that can be tapped, including unused greenbelts, idle land that has not yet been used, abandoned buildings that can be opened and upgraded.

\section{Innovation and Practice of Micro-transformation in Shuiguo Lake Community, Wuchang}

\subsection{Improvement of Facilities and Renovation of Houses}

With regard to the problems of imperfect and inconvenient living facilities in Zhangjiawan community on the streets of Shuiguo Lake, we will present the existing objective problems and suggestions for improvement to the government departments and submit a report to the government departments for the rational allocation of the plans through the joint coordination and planning of various units. For example, increase the number of public transport, increase the number of surrounding walkways and convenience shops, schools and so on. This implementation process will continue for a long time, planners and government departments and residents to participate in the research process, most of the residents put forward a lot of building repair requirements, some residents even asked to demolish and rebuild. Therefore, we view this issue as the top priority of community planning. First of all, we contact the relevant agencies to check the quality of housing in the community, testing, and submit the report to government departments; Secondly, organize the resident representative, neighborhood committee, property company and government department responsible person to carry on the discussion, negotiate the plan of the building repair, determine the duty and responsibility, make clear the repair operation detail, formulate the fund management system, etc. Finally, according to the severity of housing problems and repair type of phased construction, at the same time, in the repair process to solve the residents temporary residence, construction quality supervision, construction progress guarantee, housing acceptance and other aspects of work. 


\subsection{Organize Traffic and Improve the Environment}

The major traffic problems in the Zhangjiawan community are: The entrances and exits are congested, the walking route is unreasonable, and the parking of motor vehicles is difficult.Improvement measures mainly focus on the full excavation of community space, on the basis of this, put forward the traffic organization optimization plan, standardize the delineation of motor vehicle parking space. The safety and overall identification of the community entrance area should be improved under the condition of ensuring the smooth flow of the life passage and the firefighting passage; Based on the data obtained from behavior observation and questionnaire survey, a reasonable pedestrian walkway is set up to realize the separation of passengers and vehicles. Widening the entrance gate, changing the daily traffic conditions of non-motor vehicles and pedestrians, to meet the normal access needs of motor vehicles; Strengthen the property management and resident's supervision, promote the community traffic organization smooth, comfortable and harmonious. Environmental planning focuses on three aspects: functionality, applicability and aesthetics. The design is designed mainly through the renewal and transformation of small-scale public spaces. According to the implementation mechanism of the "Sanjiu" community microtransformation in Wuhan, which is based on the sports behavior science, it analyzes the demands of the community space of the audience group of the community population, makes full use of the existing resources, and emphasizes the compound function of the space. Provide public space for people of all ages to interact with each other.

\subsection{Practical Results of Community Micro-Transformation Design}

(1) Alteration of the entrance portal area: Separation of people and cars, standardized parking, improve the entrance area of the portal image, enhance the residents' sense of identity and belonging to the community.
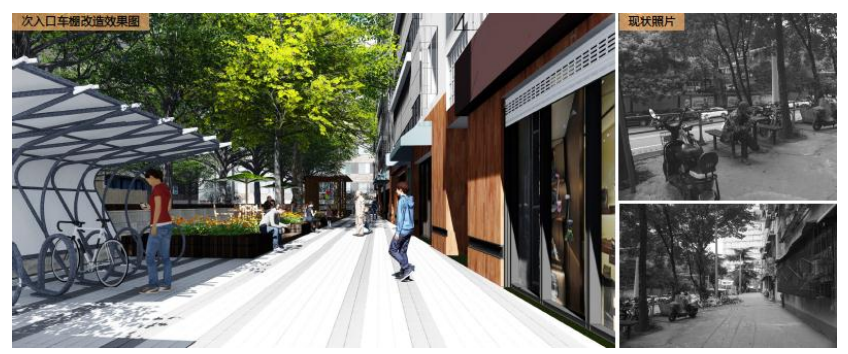

Figure 4: Community Entrance Design

(2) renovation of the Centre's area of activity: Refer to the concept of respace to update the rest seats, increase children's recreation facilities, become the main catalyst of social interaction of residents.
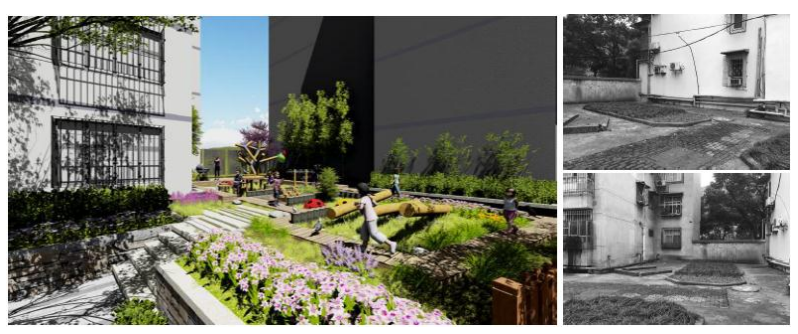

Figure 5: Children's playground Design

(3) Car park renovation: Change function sheet I. The state of the environment. The design combines the parking lot with the roof garden to increase the outdoor activity space of the community and to solve the problem of the residents in the northeast side using the nearby activity space.

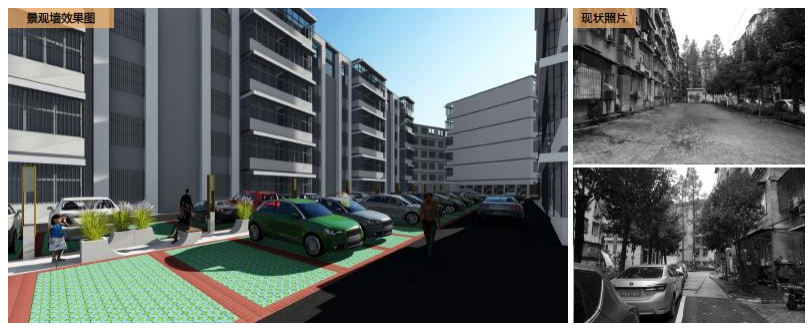

Figure 6: Community parking space planning and design

(5) West entrance Garden improvement: On the basis of not destroying the original trees, add 100 meters fitness track and rest seat area, improve the utilization rate of green space, increase outdoor activities and social space.

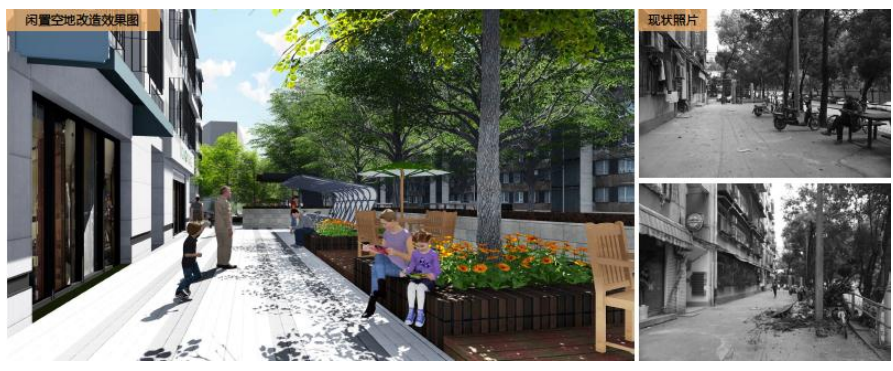

Figure 7: West entrance Garden Design

(6) Renovation of residents' Committee Fitness area: Retain the function of community service, communication and fitness, expand the space of the lounge, improve the comfort of the seats, transform the sunshine room, and create a more comfortable environment for the social and activity of the elderly.

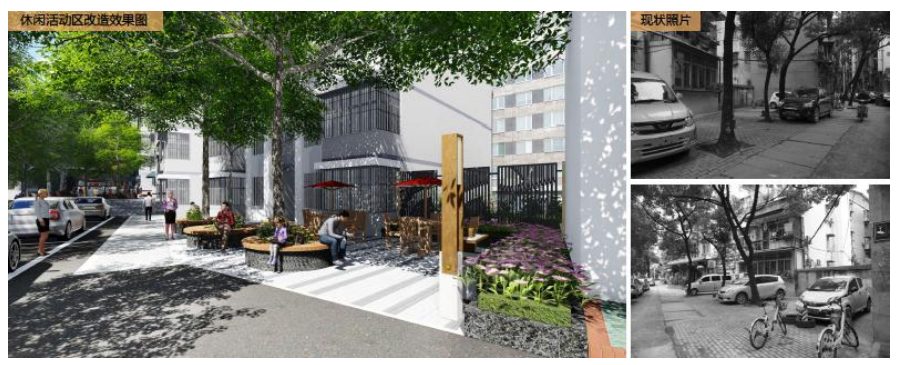

Figure 8: Committee Fitness Area Design

\section{CONCLUSION}

To sum up, the first task of community renewal practice is to try to find out a new community renewal model, which can arouse the attention of the community planning, remove the obstacles of communication and participation. make community stakeholders in the updating process more aware of their legitimate rights and obligations. As a source of professional strength reserve, in the face of the future dynamic renewal model and the new vocational branches and industries derived from it, the planners have the responsibility to contribute to the exploration of the new renewal model. And prepare for transformation and acceptance of challenges.

\section{ABOUT THE AUTHORS}

JingChen, a Ph.D pstudent at Huazhong University of science and technology, the major is new media art design.

\section{REFERENCES}

[1] Qi, B.Q., Wu, M.Q. 2009. The concept of urban renewal and the reality of Chinese cities. Journal of Urban Planning, (2), 75-82.

[2] Fang, Ke. 1998. The Development and Revelation of Western Urban Renewal. Urban Planning Journal, (1), 59-61.

[3] Du, Peng. 2016. Self-governance in micro-renewal of community environment. Times Architecture (4), 62-67.

[4] Gong, S.Z. 2016. Urban micro-renewal started with regeneration and public awareness. Times Building, (4), 29-33.

[5] Social network booting, urban micro-regeneration acting. Times Architecture, 2016 (4): 29-33.

[6] Cai, Y.J., Shi, Q.J. 2016. Urban micro-renewal based on daily demand. An exploration of Shanghai's old city in a graduation project. Times Building (4), 18-23.

[7] Yang, G.Q., Fang, J.L., Guan, Z.M. 2017. Construction of small-scale public space facilities and reproduction of social capital in built-up areas of large cities. Shanghai Urban Planning (2), 1-7.

[8] Liu, Y.L, Yin, K.S, Wei, Y., Wang, Y. 2017. Exploration of the implementation mechanism of high-density urban community gardens: A case study of Shanghai Chuangzhi Agricultural Park. Shanghai Urban Planning (2), 29-33. 